\title{
Violência contra o idoso no ambiente familiar em capital do nordeste brasileiro
}

\author{
Violence against the elderly in the family environment in capital of the northeast brazil \\ Violencia contra los mayores en el entorno familiar en la capital del noreste de brasil
}

Recebido: 21/03/2021 | Revisado: 26/03/2021 | Aceito: 07/05/2021 | Publicado: 22/05/2021

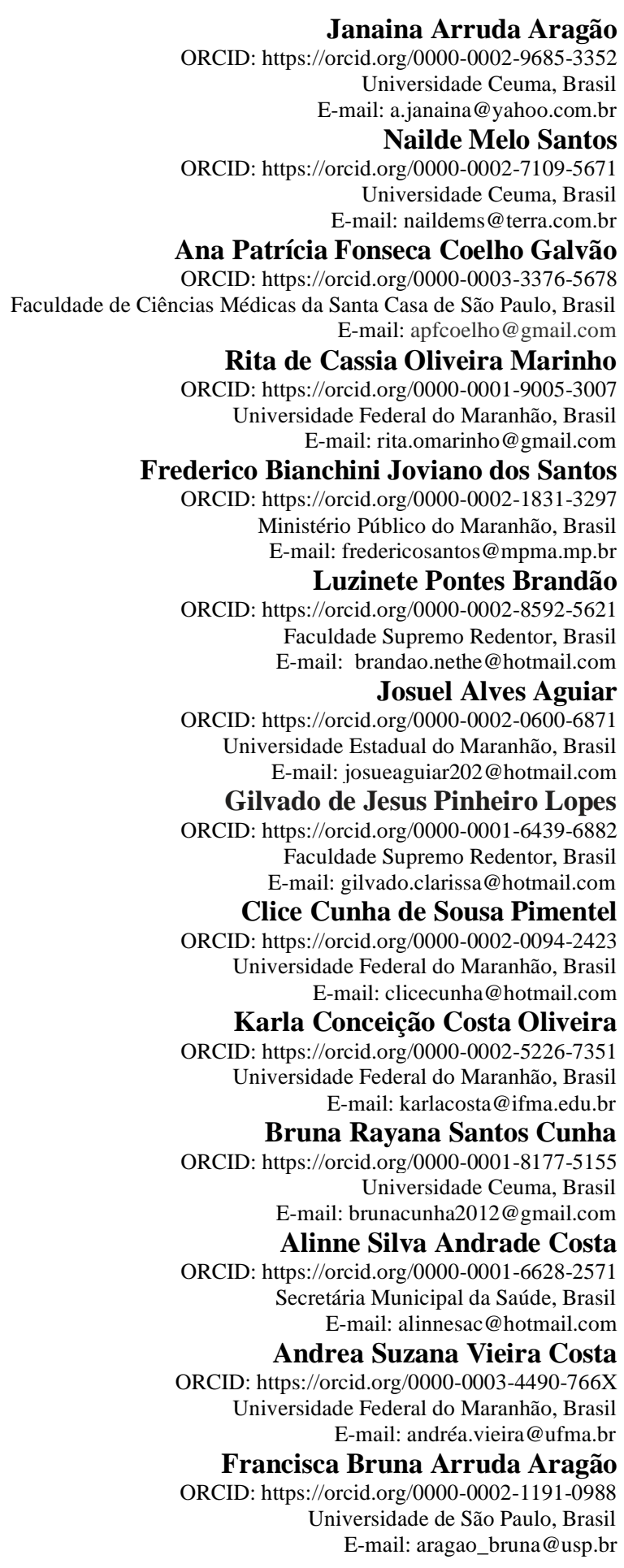




\begin{abstract}
Resumo
A violência praticada contra o idoso cresce desproporcionalmente e encontra-se inserida no convívio familiar. Isso porque ela acontece de maneira mascarada, por vínculos consanguíneos, desencadeando mudanças físicas, psicológicas e sociais. O presente estudo foi desenvolvido com o objetivo de analisar, por meio de revisão de literatura, as principais violências contra o idoso no ambiente familiar. Trata- se de uma revisão integrativa, realizada nas bases de dados Scientific Eletronic Library Online (Scielo), Biblioteca Virtual da Saúde (BVS) e Google Acadêmico. Foram pesquisados 63 artigos publicados, entre os anos de 2015 á 2020 que analisaram casos ocorrido em São Luis-MA. Após rigorosa seleção com base nos critérios de inclusão foram analisados apenas 10 artigos. Durante a pesquisa constatou-se que a violência sofrida pelo idoso no ambiente familiar em em São Luis-MA foi categorizada em tipos de agressão e motivos da agressão. Concluiu-se com esse trabalho que existe uma carência sobre esse assunto considerando-se a necessidade de intervenções mais abrangentes, aspectos primordiais para organizar e ponderar políticas públicas de proteção e valorização da pessoa idosa.
\end{abstract}

Palavras-chave: Violência doméstica; Idoso; Maus tratos ao idoso.

\begin{abstract}
The violence practiced against the elderly grows disproportionately and is part of the family life. This is because it happens in a masked way, through blood ties, triggering physical, psychological and social changes. This study was developed with the aim of analyzing, through a literature review, the main violence against the elderly in the family environment. It is an integrative review, carried out in the Scientific Eletronic Library Online (SciELO), Virtual Health Library (VHL) and Google Scholar databases. 63 published articles were searched, between the years 2015 to 2020 that analyzed cases that occurred in São Luis-MA. After rigorous selection based on the inclusion criteria, only 10 articles were analyzed. During the research it was found that the violence suffered by the elderly in the family environment in São Luis-MA was categorized into types of aggression and reasons for the aggression. It was concluded with this work that there is a lack on this subject considering the need for more comprehensive interventions, essential aspects to organize and ponder public policies for the protection and valorization of the elderly.
\end{abstract}

Keywords: Domestic violence; Elderly; Elder abuse.

\title{
Resumen
}

La violencia ejercida contra los ancianos crece de manera desproporcionada y forma parte de la vida familiar. Esto se debe a que ocurre de forma enmascarada, a través de lazos de sangre, provocando cambios físicos, psicológicos y sociales. Este estudio se desarrolló con el objetivo de analizar, a través de una revisión de la literatura, las principales violencias contra las personas mayores en el ámbito familiar. Es una revisión integradora, realizada en las bases de datos Scientific Eletronic Library Online (SciELO), Virtual Health Library (BVS) y Google Scholar. Se buscaron 63 artículos publicados, entre los años 2015 a 2020 que analizaron casos ocurridos en São Luis-MA. Tras una rigurosa selección basada en los criterios de inclusión, solo se analizaron 10 artículos. Durante la investigación se encontró que la violencia sufrida por los ancianos en el ámbito familiar en São Luis-MA fue categorizada en tipos de agresión y motivos de la agresión. Con este trabajo se concluyó que existe una carencia en este tema considerando la necesidad de intervenciones más integrales, aspectos fundamentales para organizar y ponderar las políticas públicas de protección y valorización de las personas mayores.

Palabras clave: La violencia doméstica; Anciano; Maltrato a los ancianos.

\section{Introdução}

A violência sofrida pelo idoso sempre esteve presente na história da humanidade. Ela trata-se de qualquer atitude, única ou habitual, falta de cuidados ou uma relação proveitosa que cause danos ou aborrecimento à pessoa idosa (Oliveira et al., 2013). De acordo com Lino et al., (2019), a violência contra esse idoso ocorre no mundo em grande escala, por isso a mesma engloba o meio social, independente de classe socioeconômico, etnia ou religião. De tal forma, encontra-se inserida geralmente no ambiente familiar e instituições de longa permanência. Assim os idosos ficam de conviver em coletividade, devido à coação psicológica sofrida por seu cuidador.

Diante deste contingente é primordial, a busca por limitações de agentes de risco causadores de danos físicos, emocionais e morais á idosos, pois isso configura-se como um sério problema de saúde pública e social a nível mundial (Guimarães et al., 2016).

No que tange a formulação de políticas, ações de promoções, prevenção e cuidados aos idosos, nesse âmbito doméstico e familiar, tem-se um extenso ordenamento legal de defesa, presente na Lei nº8.842/1994 também chamada de Política Nacional do Idoso. Esta lei tem por finalidade assegurar os direitos sociais do idoso, criando condições para promover sua liberdade, integração 
e cooperação efetiva na sociedade (Brasil, 1994). Em se tratando do Estatuto do Idoso, que tem por finalidade regularizar os direitos dos idosos com idade igual ou superior a 60 anos.

Segundo Santana et al. (2016), existe uma variedade de conceitos que definem o fenômeno da violência contra a pessoa idosa, entre as mais comuns cita-se a: agressão física, psicológica ou maus-tratos psicológicos, traduzidos pelas agressões verbais ou gestuais; abuso ou violência sexual; abandono; negligência; financeira ou violência patrimonial e autonegligência.

Para Crippa et al. (2016), a violência física é o uso de força corporal para ferir, provocar dor, causar lesões no corpo. Ela também pode se concretizar com a utilização de objetos que provoque danos maiores que um hematoma como, por exemplo, a incapacidade temporária ou permanente e em alguns casos a morte. A violência psicológica se caracteriza pelas agressões verbais ou gestuais com a intenção de amedrontar, menosprezar, humilhar, restringir a liberdade ou isolar o idoso do convívio social podendo levar até uma depressão. Já o abuso ou violência sexual se configura com a prática de jogos sexuais de caráter abusivo para obter excitação, onde não há consentimento do idoso ou quando este encontra-se incapacitado de consentir. Ressalta-se que essa modalidade de violência muitas vezes é imposta por aliciamento ou ameaças.

Silva e Dias (2016), afirmam que o abandono ocorre na ausência ou renúncia dos responsáveis governamentais, institucionais ou familiares que se omitem em prestar atendimento ao idoso que necessita de zelo e proteção. Já a violência patrimonial carcateriza-se pela exploração imprópria, ilegal ou não de bens financeiros ou patrimoniais por meio de ameaça. A negligência ocorre quando se tem a omissão ou restrição de cuidados essenciais com esse idoso. A autonegligência é cometida pelo idoso contra si próprio, quando deixa de praticar atos necessários para a sua saúde e bem-estar.

Rodrigues et al. (2017) diz que ainda que tenha uma grande magnitude, à abordagem dessa temática nas literaturas nacionais e internacionais tem sido insuficiente. A justificativa é porque por algumas razões perpetua-se o medo de relatar situações de conflitos, coações sociais e pessoais dos familiares e a vulnerabilidade dos obstáculos de enfrentamentar a família devido ao grau de fragilidade que se encontram os idosos nessa situação. Não obstante essa situação traz consequência no processo de senescência e senilidade.

No entanto, apesar de muitas vezes "disfarçada" pelo violentador propõe-se um olhar, mas atento dos profissionais de saúde, em especial os enfermeiros, por desempenharem um papel importante na identificação de sinais e sintomas dessas agressões, além de serem um articulador diante de outros profissionais, a combater tal problema como é determinado pela lei (Castro et al., 2018).

Com o elevado índice de violência contra o idoso, em especial no ambiente familiar é necessária haver uma análise bem detalhada sobre os fatores que contribuem para a ocorrência de agressões que ocasionam traumas psicossomáticos e corporal. Isso tendo em vista que os idosos são vulneráveis, por isso deve-se prestar uma assistência de qualidade e ter sensibilidade para estabelecer medidas de controle e prevenção dos agravos relacionados a essa violência sênior.

Diante do contexto, observa-se a necessidade de desenvolver capacitação profissional voltada ao idoso para promover a humanização, acolhimento, suporte familiar e social, percepção de fragilidade familiar. Tudo isso buscando uma articulação de diferentes setores com o intuito de desenvolver um melhor planejamento com ênfase na sistematização e avaliação de ações de prevenção e enfretamento da violência já que esse é um grave problema de saúde pública. Assim surgiu o seguinte problema: o que falta para o Estado promover políticas públicas para inibir a violência contra o idoso?

\section{Metodologia}

Trata-se de uma revisão integrativa, visto que proporciona uma síntese de conhecimentos e a incorporação da aplicabilidade de resultados e de estudos significativos, onde requer os mesmos parâmetros de rigor, compreensão e replicação aplicados aos estudos primários. 
A busca foi realizada de acordo com as seguintes etapas: 1) questão norteadora; 2) coleta de dados; 3) avaliação dos dados; 4) análise dos dados e 5) elaboração dos quadros sinópticos.

Para realização da revisão levantou-se a seguinte problemática: A violência contra o idoso no ambiente familiar é um problema de Saúde Pública? Para fazer o levantamento de dados acerca da violência contra o idoso no ambiente familiar buscou-se os seguintes descritores: idoso, violência doméstica e maus tratos ao idoso. Os dados foram levantados nas bases de dados Scientific Eletronic Library Online (Scielo), Biblioteca Virtual de Saúde (BVS) e Google Acadêmico.

Quanto aos critérios de inclusão, foram utilizados artigos disponibilizados na íntegra, textos completos no idioma português publicados nos últimos 5 anos (2015 a 2020) circunscritos na temática abordada. Assim, foram escolhidos 26 artigos na Scielo, 19 artigos na base de dados BVS e 18 artigos Google Acadêmico, após fazer uma leitura minunciosa destacando aqueles que responderam ao objetivo proposto por esse estudo para organizar e tabular os dados. À amostra constituiu-se em 10 artigos.

A coleta das informações deu-se com base em estudos selecionados, onde foi elaborado uma tabela comparativa que possibilita avaliar às evidências a partir da extração das informações, título do estudo, autor, ano, base de dados, características metodológicas, objetivo e principais resultados encontrados.

A apresentação da revisão e a discussão dos dados foi realizada de forma descritiva, através de categorias temáticas que possibilitam ao leitor à avaliação crítica dos resultados obtidos e a sua aplicabilidade.

\section{Resultados e Discussão}

Essa pesquisa foi composta por uma amostra de 10 artigos, onde todos eles abordam em seu conteúdo aspectos que refentes a violência contra o idoso no ambiente familiar. Dentre os tipos de pesquisa prevaleceu-se a pesquisa de revisão integrativa, onde o número mais alto de publicações aconteceu durante os anos de 2015 e 2019.

No quadro que segue abaixo será apresentada a descrição dos artigos que foram selecionados para compor essa pesquisa, contendo informações de autores, título do estudo, base de dados, tipo de estudo e ano:

Quadro 1- Descrição dos artigos incluídos na revisão integrativa, São Luís/MA - 2020.

\begin{tabular}{|c|c|c|c|c|c|}
\hline № & AUTOR(ES) & TÍTULO DO ESTUDO & $\begin{array}{l}\text { BASE } \\
\text { DADOS }\end{array}$ & $\begin{array}{l}\text { TIPO DE } \\
\text { ESTUDO }\end{array}$ & ANO \\
\hline 1 & $\begin{array}{l}\text { RODRIGUES, Ivalda Siva } \\
\text { et al. }\end{array}$ & $\begin{array}{l}\text { Violência contra a pessoa idosa nas } \\
\text { pesquisas em saúde: Revisão } \\
\text { Integrativa }\end{array}$ & BVS & $\begin{array}{l}\text { Revisão } \\
\text { Integrativa }\end{array}$ & 2015 \\
\hline 2 & $\begin{array}{l}\text { CAMACHO, Alessandra } \\
\text { Conceição Leite Funchal; } \\
\text { ALVES, Rosemere Rosa. }\end{array}$ & $\begin{array}{l}\text { Maus tratos contra os idosos na } \\
\text { perspectiva da enfermagem: } \\
\text { revisão integrativa }\end{array}$ & BVS & $\begin{array}{l}\text { Revisão } \\
\text { Integrativa }\end{array}$ & 2015 \\
\hline 3 & $\begin{array}{l}\text { MUSSE, Juliana de } \\
\text { Oliveira; RIOS Maria } \\
\text { Helena Evangelista. }\end{array}$ & $\begin{array}{l}\text { Atuação do enfermeiro perante a } \\
\text { violência doméstica sofrida pelo } \\
\text { ldoso }\end{array}$ & SciELO & Quantitativa & 2015 \\
\hline 4 & $\begin{array}{l}\text { ROCHA, Regina da } \\
\text { Cunha et al. }\end{array}$ & $\begin{array}{l}\text { A(des) informação da violência } \\
\text { contra a pessoa idosa no Brasil }\end{array}$ & $\begin{array}{l}\text { Google } \\
\text { Acadêmico }\end{array}$ & $\begin{array}{l}\text { Revisão } \\
\text { Integrativa }\end{array}$ & 2016 \\
\hline 5 & $\begin{array}{l}\text { GOES, Adriana Lima de; } \\
\text { CEZARIO, Kariane } \\
\text { Gomes. }\end{array}$ & $\begin{array}{l}\text { Atuação da equipe de saúde da } \\
\text { família na atenção ao idoso em } \\
\text { situação de violência: revisão } \\
\text { integrativa }\end{array}$ & BVS & $\begin{array}{l}\text { Revisão } \\
\text { Integrativa }\end{array}$ & 2017 \\
\hline 6 & $\begin{array}{l}\text { RIZZIERI, Thaís Luana; } \\
\text { BARBOSA Aliny. }\end{array}$ & $\begin{array}{l}\text { Maus tratos ao idoso: revisão de } \\
\text { literatura }\end{array}$ & $\begin{array}{l}\text { Google } \\
\text { Acadêmico }\end{array}$ & $\begin{array}{c}\text { Revisão } \\
\text { Integrativa }\end{array}$ & 2017 \\
\hline 7 & $\begin{array}{l}\text { LOPES, Emmanuel Dias } \\
\text { de Sousa et al. }\end{array}$ & $\begin{array}{l}\text { Maus-tratos a idosos no Brasil: uma } \\
\text { revisão integrativa }\end{array}$ & SciELO & $\begin{array}{l}\text { Revisão } \\
\text { Integrativa }\end{array}$ & 2018 \\
\hline 8 & $\begin{array}{l}\text { MATOS, Neusa Moreira } \\
\text { et al. }\end{array}$ & $\begin{array}{l}\text { Perfil do agressor de pessoas } \\
\text { idosas atendidas em um centro de } \\
\text { referência em geriatria e } \\
\text { gerontologia do Distrito Federal, } \\
\text { Brasil }\end{array}$ & SciELO & Quantitativa & 2019 \\
\hline
\end{tabular}




\begin{tabular}{|l|l|l|l|l|l|}
\hline $\mathbf{9}$ & $\begin{array}{l}\text { SANTOS, Ana Maria } \\
\text { Ribeiro et al. }\end{array}$ & $\begin{array}{l}\text { Violência financeiro-patrimonial } \\
\text { contra idosos: revisão integrativa }\end{array}$ & SciELO & $\begin{array}{c}\text { Revisão } \\
\text { Integrativa }\end{array}$ & 2019 \\
\hline $\mathbf{1 0}$ & $\begin{array}{l}\text { POLTRONIERI, Bruno } \\
\text { Costa et al. }\end{array}$ & $\begin{array}{l}\text { Análise do tema violência nas } \\
\text { políticas de cuidado de longa } \\
\text { duração ao idoso }\end{array}$ & SciELO & $\begin{array}{c}\text { Revisão } \\
\text { Integrativa }\end{array}$ \\
\hline
\end{tabular}

Fonte: Mafra \& Rodrigues (2020).

Para um estudo mais fundamentado e decorrente à discussão dos resultados, o quadro que segue demonstra os objetivos e principais resultados encontrados:

Quadro 2- Distribuição dos resultados em relação aos tipos de violência e motivos de agressões em São Luís/MA no ano de 2020.

\begin{tabular}{|c|c|c|c|}
\hline № & AUTOR/ANO & OBJETIVOS & $\begin{array}{lcll}\text { TIPOS DE } & \text { AGRESSÃO/ MOTIVOS } \\
\text { AGRESSÕES } & & \end{array}$ \\
\hline 1 & $\begin{array}{l}\text { RODRIGUES, Ivalda Siva et al. } \\
\text { (2015). }\end{array}$ & $\begin{array}{l}\text { Analisar a produção científica } \\
\text { sobre a violência contra a pessoa } \\
\text { idosa. }\end{array}$ & $\begin{array}{l}\text { Agressão física e desrespeito, maus-tratos } \\
\text { psicológicos, autonegligência, abuso sexual e } \\
\text { financeiro, maus-tratos econômicos e emocionais, } \\
\text { violência familiar, violência sexual, violência } \\
\text { psicológica. }\end{array}$ \\
\hline 2 & $\begin{array}{l}\text { CAMACHO, Alessandra } \\
\text { Conceição Leite Funchal; } \\
\text { ALVES, Rosemere Rosa } \\
\text { (2015). }\end{array}$ & $\begin{array}{l}\text { Identificar às estratégias } \\
\text { preventivas de intervenção da } \\
\text { enfermagem para evitar os maus- } \\
\text { tratos aos idosos. }\end{array}$ & $\begin{array}{l}\text { Evidenciou-se violência abandono/ negligência, } \\
\text { autonegligência como os tipos violência que mas } \\
\text { acontece. }\end{array}$ \\
\hline 3 & $\begin{array}{l}\text { MUSSE, Juliana de Oliveira; } \\
\text { RIOS Maria Helena } \\
\text { Evangelista.(2015) }\end{array}$ & $\begin{array}{l}\text { Objetivou-se conhecer a atuação dos } \\
\text { enfermeiros perante a violência } \\
\text { doméstica contra o idoso. }\end{array}$ & $\begin{array}{l}\text { Abandono como o tipo de violência maior percentual, } \\
\text { seguido da negligência e abusos financeiros, os } \\
\text { menores percentuais foram a violência física e } \\
\text { psicológica. }\end{array}$ \\
\hline 4 & $\begin{array}{l}\text { ROCHA, Regina da Cunha et al. } \\
(2016)\end{array}$ & $\begin{array}{l}\text { A violência praticada contra idosos } \\
\text { constitui fenômeno complexo, } \\
\text { multifatorial e crescente no mundo, o } \\
\text { que torna a produção cientifica } \\
\text { instrumento importante para a } \\
\text { vigilância, dimensionamento e e } \\
\text { enfrentamento do problema. }\end{array}$ & $\begin{array}{l}\text { Causas predominantes para agressão, idade } \\
\text { avançada, necessidades de ajuda decorrente do } \\
\text { declínio da saúde mental, comportamento cognitivo/ } \\
\text { funcional. }\end{array}$ \\
\hline 5 & $\begin{array}{l}\text { GOES, Adriana Lima de; } \\
\text { CEZARIO, Kariane Gomes. } \\
\text { (2017) }\end{array}$ & $\begin{array}{l}\text { Identificar a produção científica } \\
\text { relativa à atuação da Equipe de } \\
\text { Estratégia de Saúde da Família na } \\
\text { atenção ao idoso em situação de } \\
\text { violência. }\end{array}$ & $\begin{array}{l}\text { Motivos de agressão mais comuns são conflitos } \\
\text { financeiros, dependência do convívio, capacidadee } \\
\text { diminuída, uso de álcool e drogas, } \\
\text { desentendimentos, isolamento e comunicação } \\
\text { precária. }\end{array}$ \\
\hline 6 & $\begin{array}{l}\text { RIZZIERI, Thaís Luana; } \\
\text { BARBOSA } \\
\text { Aliny. (2017) }\end{array}$ & $\begin{array}{l}\text { Compreender, com base nos } \\
\text { expostos em literaturas consultadas } \\
\text { os fatores apontados que fortalecem } \\
\text { as diversas modalidades de maus } \\
\text { tratos causados aos idosos. }\end{array}$ & $\begin{array}{l}\text { A violência física e psicológica apresentou um índice } \\
\text { maior no período, seguida da violência financeira, } \\
\text { sexual e negligência. }\end{array}$ \\
\hline 7 & $\begin{array}{l}\text { LOPES, Emmanuel Dias de } \\
\text { Sousa et al. (2018) }\end{array}$ & $\begin{array}{l}\text { Objetivou a realização de uma } \\
\text { revisão integrativa da literatura sobre } \\
\text { o conhecimento científico produzido } \\
\text { no Brasil entre os anos de } 2013 \text { a } \\
2017 \text {, enfatizando a ocorrência de } \\
\text { maus-tratos contra idosos. }\end{array}$ & $\begin{array}{l}\text { Os principais tipos de violência evidenciados foram: } \\
\text { psicológica, física, financeira, auto abandono, } \\
\text { negligência e violência verbal. }\end{array}$ \\
\hline 8 & $\begin{array}{l}\text { MATOS, Neusa Moreira et } \\
\text { al. (2019) }\end{array}$ & $\begin{array}{l}\text { Traçar o perfil do agressor de } \\
\text { pessoas idosas atendidas em um } \\
\text { centro de referência em geriatria e } \\
\text { gerontologia do Distrito Federal, } \\
\text { Brasil, entre os anos de } 2008 \text { a } \\
2018 \text {. }\end{array}$ & $\begin{array}{l}\text { O uso abusivo de álcool, drogas ilícitas pelo agressor é } \\
\text { um dos fatores predominantes, demência, doenças } \\
\text { crônicas. }\end{array}$ \\
\hline 9 & $\begin{array}{l}\text { SANTOS, Ana Maria Ribeiro et } \\
\text { al. (2019) }\end{array}$ & $\begin{array}{l}\text { Analisar às evidências disponíveis na } \\
\text { literatura de enfermagem acerca da } \\
\text { violência financeiro-patrimonial } \\
\text { contra idosos }\end{array}$ & $\begin{array}{l}\text { Redução na renda familiar, tratamentos e compra de } \\
\text { medicamentos, esgotamento físico e mental, uso de } \\
\text { drogas ilícitas, sobrecarga do cuidador, apropriação de } \\
\text { bens materiais e financeiros. }\end{array}$ \\
\hline
\end{tabular}




\begin{tabular}{|c|c|c|c|}
\hline 10 & $\begin{array}{l}\text { POLTRONIERI, Bruno Costa et } \\
\text { al. (2019) }\end{array}$ & $\begin{array}{l}\text { Identificar e analisar na literatura } \\
\text { nacional e internacional se é comum } \\
\text { o tema da violência ser abordado nos } \\
\text { estudos de políticas públicas de } \\
\text { atenção ao idoso albergado em } \\
\text { instituição de longa permanência } \\
\text { para idosos. }\end{array}$ & $\begin{array}{l}\text { Abusos físicos, psicológicos, sexuais e negligência, } \\
\text { afirmando que as violências, mais recorrentes são a } \\
\text { negligência, o abandono e a autonegligência. }\end{array}$ \\
\hline
\end{tabular}

Fonte: Mafra \& Rodrigues (2020).

Para discussão dos dados encontrados acima, categorizou-se os resultados em dois eixos centrais, quais sejam: tipos de agressão e motivos da agressão.

\subsection{Tipos de agressão}

Em seu estudo, Rodrigues et al. (2015), relata que a violência e os maus-tratos a idosos concernem aos abusos ou maus tratos físicos, psicológicos, violência sexual, abandono, negligências, abusos financeiros e autonegligência. Nessa sequência, compreende-se por violência prática ou omissão aquela que causa dano ou aflição e resulta em sofrimento, intimidação, calúnia, ferimentos, tortura, inutilidade, fraturas ósseas, ruptura de ligamentos, cicatrizes e isolamento do convívio social.

Conforme a perspectiva do autor acima citado, observa-se a questão do medo e dificuldades do idoso em denunciar as violências sofridas no seu ambiente de convívio por medo de represália por parte do familiar agressor, com isso deve-se incentivar e contribuir com maior divulgação e notificação de informações para subsidiar a construção de políticas públicas nesse tocante e que promovam uma saúde e qualidade de vida.

Para Camacho e Alves (2015), enfatiza-se que a desestruturação familiar desencadeia o abandono ou negligência. Assim esse idoso fica vulnerável, desprotegido e deixado em instituições especializadas em cuidar de idosos. Quando se refere à autonegligência, ocorre um descuidado com sua saúde, pois nãe é providenciado comida, medicamentos ou outras necessidades para si próprios, e podem ignorar sua higiene.

Contudo, em relação aos tipos de violências, Musse e Rios (2015), disseram que as violências intrafamiliares mais comuns percebidas por profissionais são: a negligência, o abandono, a violência econômica, a psicológica, à autonegligência, a violência física e outras. Quando ocorre às violências praticadas no ambiente de convívio desse ser vulnerável elas acabam tirando valores como a qualidade de vida e o vínculo afetivo de paz.

Poltronieri et al. (2019) diz que a violência contra o idoso é estabelecida de várias formas como: abusos físicos, psicológicos, sexuais e negligência. Afirma-se ainda que às violências mais recorrentes são: a negligência, o abandono e a autonegligência. Ainda sob a visão do autor citado, devido a carência socioeconômica que muitas famílias enfrentam, fica difícil de perceber a tênue linha que desencadeia os problemas para atender às carências do idoso negligênciado.

Segundo Rizzieri e Barbosa (2017) em seu estudo a violência física e psicológica apresentou um índice maior no período estudado. Em seguida vem violência financeira, sexual e a negligência. Em sua grande maioria às violências contra o idoso são praticadas por filhos do sexo masculino. Essas informações mostram o quanto os vínculos consanguíneos encontram-se desgastados, são também superficiais e inconstantes. Na verdade, o ambiente familiarque deveria ser um lugar de abrigo e proteção, mas acaba transforma-se, com o decorrer do tempo, em um lugar agressivo e hostil.

Percebeu-se que os principais tipos de violência encontrados por Lopes et al. (2018) em seu levantamento foram: psicológica (28\%), física (28\%), financeira (12\%), outros tipos de violência (12\%) e outras que não foram descritas (20\%). Outro fator verificado foi a proximidade entre a vítima e o agressor, pois constantemente é cometido por filhos (28\%) e tendo a própria residência (60\%) como o principal local de violência. Algumas causas relatadas para existir a violência contra o idoso é que o ambiente familiar em diversas ocasiões é estressante e compreende-se a existência de parentes tensos e despreparados. 
Mantendo-se sob o enfoque dos autores acima citados, no que diz respeito a percepção dos tipos de agressões cometidas no contexto familiar, às pesquisas denotam a esperança de que a família exerça a função de sustentar e acolhedor esse idoso para regredir esse método incoerente, visto que na maioria das vezes a violência nasce no seio da família, ou seja, é cometida por membros consanguíneos.

\subsection{Motivos da agressão}

Em seu estudo, Goes e Cezario (2017) relata que os motivos mais relevantes para haver à agressão contra esse idoso são conflitos financeiros entre membros da família, relação de dependência do convívio, o fato de o idoso ter capacidade diminuída, o familiar ter problemas com álcool e drogas, desentendimentos, isolamento do idoso, comunicações precárias. Isso tudo possibilita motivos para o cuidador cometer essas agressões, sendo que na grande maioria das vezes essas agressões ocorrem por parte de parentes próximos como já explicado.Entretanto, esses idosos sofrem traumas físicos e psicológicos que causam sequelas de curto a longo prazo.

Apesar da família ser o eixo essencial de apoio e suporte familiar para esse idoso, na maioria das vezes, o responsável por ele nunca encontra-se preparado para assumir o papel de cuidador ou encontra-se despreparado para cumprir com às atribuições a ele designadas que é: proteger, zelar, orientar e administrar os bens. Isto é quando não provém de bens a relação se torna mais difícil devido a dependência financeira que o idoso passa a ter para o custeio de suas necessidades com alimentos e remédios.

Todavia, de acordo com Santos et al., (2019) cuidar de idosos pertencentes à residência traz modificações e adequações na rotina de vida do familiar, causando impacto e desconforto. Portanto necessitarão fazer mudanças em seus estilos de vida, onde acontecem redução na renda familiar devido a tratamentos e compra de medicamentos, esgotamento físico e mental, uso descontrolado de drogas lícitas, sobrecarga do cuidador, apropriação de bens materiais e aposentadorias, esse idoso no ponto de vista do responsável traz limitação no seu cotidiano.

Em consonância com o autor acima citado, um dos motivos da agressão que mais acontecem contra esse idoso é o financeiro e patrimonial. Essa modalidade de agressão encontra-se presente em distintos lugares mediate interesses, compreensão e fragilidade sociais, econômicas e funcionais.

Para Matos et al., (2019) o uso abusivo do álcool ou drogas ilícitas pelo agressor é um dos fatores predominantes na ocorrência de violências. Em outros casos os idosos apresentam demência, doenças crônicas (diabetes, hipertensão e renal crônica), doenças neurodegenerativas (Alzheimer e Parkinson) dentre outras. Isso tudo acaba causando uma certa dificuldade de convívio, ou seja, às relações consanguíneas se tornam conflituosas devido a magnitude de responsabilidade que esse cuidador tem que enfrentar.

Portanto da análise feita acima observou-se que dificuldades de enfrentamento do envelhecimento ocasiona a ocorrência de agressões, logo no momento em que o idoso mais necessita de ajuda decorrente do: declínio da saúde mental, comportamento cognitivo e funcional. Isso, sendo que quem deveria cuidar dos idosos são às pessoas que têm vínculo familiar com eles ou coabitam. Mas a realidade é diferente e a violência contra o idoso ocorre com mais frequência tendo como autor o filho homem que apresenta alto grau de estresse elevado, disfunções patológicas ou conflito familiar do idoso (Rocha et al., 2016).

\section{Conclusão}

Diante de todo o exposto concluiu-se a resposta para o problema apresentado na introdução é que o que falta para o Estado promover políticas públicas para inibir a violência contra o idoso é perceber que esse é um problema que afeta, ainda que indiretamente, todas as camadas sociais e deve ser tratado com mais seriedade, uma vez que os gastos com médicamentos, tratamento e assistência judicial ao idoso agredido é mais alto que uma política efetiva de enfretamento. 
Constatou-se com essa pesquisa que a violência contra o idoso no ambiente familiar constitui-se como um problema de saúde pública, cuja dimensão ocorre em grande proporção na população. Diante disso, reitera-se ser indispensável a competência técnica de verificar e identificar às reais necessidades de ordem física, psicológica ou social da pessoa idosa, posteriormente permitindo mudanças nos paradigmas de a promoção de ações com políticas públicas e questões sociais.

À agressão que esses idosos sofrem no seu ambiente de convívio é marcada por um enfrentamento mais efetivo na resolução de tal problemática, como demonstrado no estudo. Portanto, identificou-se que cabe fazer considerações pertinentes devido a sobrecarga dos familiares com o idoso dependente e verificou-se os tipos de agressões mais comuns sofridas por esses idosos.

Além disso, torna-se necessário a realização de novas pesquisas acerca da temática abordada, considerando-se a necessidade de intervenções de forma mais abrangente, bem como trazer aspectos primordiais para organizar e ponderar políticas públicas de proteção e devalorização da pessoa idosa. Sendo assim, considera-se que por se tratar de uma revisão integrativa funciona como um instrumento para futuros pesquisadores que tiverem interesse sobre o tema.

\section{Referências}

Brasil. Ministério da Saúde. Lei $\mathrm{n}^{\circ}$ 10.741, $1^{\circ}$ de outubro de 2003 (2003) Estatuto do Idoso /Ministério da Saúde. <https://bvsms.saude.gov.br/bvs/publicacoes/estatuto_idoso_3edicao.pdf >

Brasil. Lei $\mathrm{n}^{\circ}$ 8.842, 4 de janeiro de 1994. Dispõe sobre a política nacional do idoso, cria o Conselho Nacional do Idoso e dá outras providências. Diário Oficial da União, Brasília, DF. <http://www.planalto.gov.br/ccivil_03/leis/18842.htm>

Camacho, A. C. L.F. \& Alves, R. R. (2015). Maus tratos contra os idosos na perspectiva da enfermagem: revisão integrativa. Rev. enferm. UFPE on line. Niterói (RJ), Vol 9. <https://periodicos.ufpe.br/revistas/revistaenfermagem/article/view/10418>.

Castro, V. C. de \& Rissardo, L. K. \& Carreira, L. (2018) Violência contra os idosos brasileiros: uma análise das internações hospitalares. Rev. Bras. Enferm., Brasília,v. 71, supl.2, p. 777-785. <http://www.scielo.br/scielo.php?script=sci_arttext\&pid=S0034-71672018000800777\&lng=pt\&nrm=iso>.

Crippa, A. et al. Violência contra pessoa idosa a partir da análise de boletins de ocorrência. Revista Sistema Penal \& Violência. Rio Grande do Sul, v. 8, n. 2 (2016). $<$ https://revistaseletronicas.pucrs.br/ojs/index.php/sistmapenaleviolencia/article/view/24134>.

Goes, A. L.\& Cezario, K. G. (2017) Atuação da equipe de saúde da família na atenção ao idoso em situação de violência: revisão integrativa. Arquivos de Ciências da Saúde, [S.1.], v. 24, n. 2, p. 100-10. ISSN 2318-3691. <http://www.cienciasdasaude.famerp.br/index.php/racs/article/view/638>.

Guimarães, D. B. O. et al (2016) Caracterização da pessoa idosa vítima de violência. Rev. enferm. UFPE on line, Pernambuco, 10(supl.3): 1343-1350. Ilus. <https://pesquisa.bvsalud.org/portal/resource/pt/bde-30219>.

Lino, V.T. S. et al (2019). Prevalência e fatores associados ao abuso de cuidadores contra idosos dependentes: a face oculta da violência familiar. Ciênc. saúde coletiva, Rio de Janeiro, v. 24, n. 1, p. 87-96. <http://www.scielo.br/scielo.php?script=sci_arttext\&pid=S1413-81232019000100087\&lng=en\&nrm=iso>.

Lopes, E. D. de S. et al (2018) Maus - tratos a idosos no Brasil: uma revisão integrativa. Rev. bras. geriatr. gerontol., Rio de Janeiro, v. 21 , n. 5, p. 628-638. <http://www.scielo.br/scielo.php?script=sci_arttext\&pid=S1809-98232018000500628\&lng=pt\&nrm=iso>.

Matos, N. M.de et al (2019) Perfil do agressor de pessoas idosas atendidas em um centro de referência em geriatria e gerontologia do Distrito Federal, Brasil. Rev. bras. geriatr. gerontol., Rio de Janeiro, v. 22, n. 5, e190095. <http://www.scielo.br/scielo.php?script=sci_arttext\&pid=S1809$98232019000500206 \& \operatorname{lng}=$ pt\&nrm=iso>.

Musse, J. de O.; RIOS, M. H. E. (2015). Atuação do enfermeiro perante a violência doméstica sofrida pelo idoso. Estud. interdiscip. envelhec.,Salv ador, BH.20:365 - 379. Ilus. <https://pesquisa.bvsalud.org/portal/resource/pt/biblio-834541>.

Oliveira, A. A. V. de et al. Maus-tratos a idosos: revisão integrativa da literatura. Rev. bras. enferm., Brasília , DF. v. 66, n. 1, p. 128-133, fev. 2013. <http://www.scielo.br/scielo.php?script=sci_arttext\&pid=S0034-71672013000100020\&lng=pt\&nrm=iso>.

Poltronieri, B. Costa, S., Edinilsa R. \& Ribeiro, A. P. (2015) Análise do tema violência nas políticas de cuidado de longa duração ao idoso. Ciênc. saúde coletiva, Rio de Janeiro, v. 24, n. 8, p. 2859-287. <http://www.scielo.br/scielo.php?script=sci_arttext\&pid=S1413-81232019000802859\&lng=pt\&nrm=iso>.

Rizzieri, T. L. \& Barbosa, A (2017) Maus tratos ao idoso: revisão de integrativa., Rev. saúde em foco, Amparo, SP, Edição no 9. <http://portal.unisepe.com.br/unifia/wpcontent/uploads/sites/10001/2018/06/047_maus.pdf>.

Rocha, R da C et al (2016) A (des) informação da violência contra a pessoa idosa no brasil: revisão integrativa da literatura. Rev. Med. Minas Gerais. Belo Horizonte, MG, V.26, (supl8): S5-S10. <http://rmmg.org/artigo/detalhes/2113>.

Rodrigues, I. S. et al (2015) Violência contra a pessoa idosa nas pesquisas em saúde: revisão integrativa. Rev. enferm. UFPE on line. Recife, 9(3):7126-32. $<$ https://scholar.google.com.br/scholar?hl=pt-BR\&as_sdt=2005\&sciodt=0\%2C5\&cites=2263305577679538566\&scipsc=1\&q=\&btnG=>.

Rodrigues, R. A. P. et al (2017). Violência contra idosos em três municípios brasileiros. Rev. Bras. Enferm., Brasília , v. 70, n. 4, p. 783-791. 
Research, Society and Development, v. 10, n. 6, e10210614103, 2021 (CC BY 4.0) | ISSN 2525-3409 | DOI: http://dx.doi.org/10.33448/rsd-v10i6.14103

<http://www.scielo.br/scielo.php?script=sci_arttext\&pid=S0034-71672017000400783\&lng=pt\&nrm=iso>.

Santana, I. O., Vasconcelos, D. C. de \& Coutinho, M. P. L. (2016) Prevalência da violência contra o idoso no Brasil: revisão analítica. Arq. bras. psicol., Rio de Janeiro, v. 68, n. 1, p. 126-139, abr. 2016. <http://pepsic.bvsalud.org/scielo.php?script=sci_arttext\&pid=S1809-52672016000100011\&lng=pt\&nrm=iso>.

Santos, A. M. R. dos et al (2019) Violência financeiro-patrimonial contra idosos: revisão integrativa. Rev. Bras. Enferm., Brasília , v. 72, supl. 2, p. 328-336. <http://www.scielo.br/scielo.php?script=sci_arttext\&pid=S0034-71672019000800328\&lng=pt\&nrm=iso>.

Silva, C. F. S. \& Dias, C. M. de S. B. (2016) Violência Contra Idosos na Família: Motivações, Sentimentos e Necessidades do Agressor. Psicol. cienc. prof., Brasília, DF, v. 36, n. 3, p. 637-652. <http://www.scielo.br/scielo.php?script=sci_arttext\&pid=S1414-98932016000300637\&lng=pt\&nrm=iso> 